\title{
PENGARUH KEDISIPLINAN KERJA TERHADAP KINERJA KARYAWAN PADA PT. SUBUR MAKMUR SENTOSA CABANG CIKUPA TANGERANG
}

\author{
Baliyah Munadjat , Bulan Oktrima \\ Dosen Fakultas Ekonomi, Universitas Pamulang \\ Dosen02162@unpam.ac.id, Dosen00790@unpam.ac.id
}

\begin{abstract}
Abstrak
Tujuan dari penelitian ini adalah untuk menemukan hubungan antara pengaruh disiplin dan gaya kepemimpinan terhadap kinerja karyawan. Oleh karena itu hipotesis ini dibuat untuk mengetahui bahwa terdapat pengaruh yang positif dan signifikan baik secara parsial ataupun secara simultan antara variabel-variabel independent dan dependent. Metodeatau model yang gunakan olehpenelitidanpenelitian adalah kuantitatif yang bersifat deskriptif analisis. Populasi dalam penelitian ini ialah karyawan PT. Subur Makmur Sentosa cabang Cikupa, Tangerang yang berjumlah 85 orang dan menggunakan teknik sampling jenuh dimana jumlah populasi dijadikan sampel, sehingga sampel yang digunakan dalam penelitian ini sebanyak 85 orang karyawan. Metode analisis yang digunakan dalam penelitian ini adalah analisis regresi linier sederhana (uji t).

Hasildaripenelitianinimenunjukanbahwapengujiankoefisienkorelasididapatlahh asil 0,698 yang berartiada pengaruh yang kuat antara variabel $\mathrm{X}$ dan variabel $\mathrm{Y}$. Ini menunjukkan bahwa ukuran kontribusi dari disiplin kinerja karyawan adalah 48\%, dilainitusebanyak52\% dipengaruhi oleh faktor-faktor lain. Dari hasil pengolahan data, uji-t diperoleh $t_{\text {hitung }}(8,879)>t_{\text {tabel }}(1,989)$ dengan taraf signifikansi $5 \%$ pada area penerimaan $\mathrm{Ha}$, artinya Ho ditolak, kesimpulannyaterdapat pengaruh yang kuatatausignifikan antara disiplin kerja pada kinerja karyawan.
\end{abstract}

Kata kunci: KinerjadanDisiplin

\section{ABSTRACT \\ THE EFFECT OF WORK DISCIPLINE ON EMPLOYEE PERFORMANCE IN PT. SUBUR MAKMUR SENTOSA BARANCH CIKUPA TANGERANG}

The purpose of this reserch was to find a relationship between the influence of discipline and leadership style on employee performance. Therefore this hypothesis is made to find out that there are positive and significant influences either partially or simultaneously between independent and dependent variables. The method or model used by researchers and research is quantitative descriptives analysis. Of populations in this resercheswereemployes ofSuburMakmurSentosaCikupa branch, Tangerang which numbered 85 people and used a saturated sampling technique where the population was sampled, so that the samples used in this study were 85 employees. The analytical method used in this study is simple linear regression analysis ( $t$ test).

The results of this reserch indicated that testing the correlation coefficient is 0.698 , which mean that there's a stronger influence to be variables $\mathrm{X}$ and variables $\mathrm{Y}$. This shows that the size of the contribution from discipline to employee performance is $48 \%$, amd the other side $52 \%$ influenced by other factors. Based on the results of the t-test obtained tcount $(8.879)>t$ table $(1,989)$ with a significance level of $5 \%$ in the Ha acceptance area, it means that Ho is rejected, the conclusion there is a strong or significant influence between work discipline on employee performance.

Key Word: Performance and Discipline 
JURNAL ILMIAH

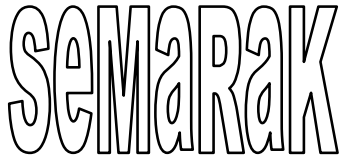

PENDAHULUAN

\section{A. Latar Belakang}

Kemajuan yang didapatolehsuatu negara sangat dipengaruhi oleh beberapafaktor yang sangat penting, yaitu memiliki staf yang berkualitas dan kompeten di bidang dan disiplin ilmu yang ditempati.Sudahselayaknyaapabilasuatuperusahaa nmemilikisumberdayamanusia yang berkualitasdanberkompetendibidangnya, makakaryawantersebutakanmampumenjawabsetia ptantanganperubahan yang akanterjadi, khususnyadalambidangusahadanorganisasi.

Hal ini tidak terlepas dari kedisiplinan setiap anggota karyawan yang akan menjadi tokoh sentral dari seluruh upaya organisasi untuk menjalankan visi dan misi yang sudah dicanangkan dari awal organisasi terbentuk. Kedisiplinan yang baik harus memenuhi 3 (tiga) tujuan yang baik, yaknoi pembentukan karakter kendali positif, pembentukan kinerja, dan perbaikan tarafhidup. Dilema yang berkembang saat ini adalah bagaimana karyawan dengan disiplin yang baik akan selalu menghargai waktu dan pekerjaannya walaupun tidak diawasi oleh atasan, dan karyawan dengan disiplin kurang baik adalah karyawan yang bekerja secara tidak efektif, tidak efisien dan tidak menghargai waktu dikarenankan tidak diawasi oleh atasannya. Pada akhirnya karyawan dengan disiplin yang baik karena waktu kerja akan menyelesaikan tugas dan tanggung jawab organisasi sesusai dengan target yang direncanakan.

Dari hak tersebut diatas PT. Subur Makmur Sentosa, Tangerang ingin menilai kinerja kedisiplinan karyawannya agar dapat bekerja dengan efektif, efisien dan dapat menghargai waktu kerja dengan tujuan agar tujuan perusahaan dapat tercapai. Dan berikut ini data empiris menganai catatan kedisiplinan PT. Subur Makmur Sentosa cabang Cikupa Tangerang dari tahun ke tahun:
Tabel. 1.1

\begin{tabular}{|l|l|c|c|c|c|c|}
\hline No. & Tahun & Jumlah & Fakit & & Tanpa & \\
& & Karyawa & & Iji & Keteran & Jumla \\
\hline 1. & 12 & 85 & 52 & 53 & 66 & 71 \\
\hline 2. & 13 & 85 & 80 & 50 & 45 & 75 \\
\hline 3. & 14 & 85 & 75 & 40 & 50 & 65 \\
\hline 4. & 15 & 85 & 70 & 60 & 60 & 90 \\
\hline 5. & 16 & 85 & 75 & 60 & 58 & 93 \\
\hline
\end{tabular}

Sumber: PT. Subur Makmur Sentosa cabang

Cikup Tangerang

Dari tabel diatas dapat diketahui tingkat kedisiplinan karyawan dalam hal waktu kerja dari tahun 2012-2016, terdapat kenaikan ketidak disiplinan karyawan dari tahun ke tahun dimana awal tahun 2012 jumlah karyawan yang tidak hadir sebanyak 171 orang dan meningkat pada tahun 2016 menjadi 193 orang yang tidak hadir selama 1 tahun periode.

Apabila tingkat ketidak disiplinan dalam hal waktu kerja tidak segera diperbaiki maka akan mengganggu kinerja PT. Subur Makmur Sentosa dan tujuan dari perusahaan tidak akan tercapai dengan maksimal, oleh karena itu diperlukan suatu respon yang positif agar kedisiplinan karyawan dapat terjaga dengan baik dan tujuantujuan yang sudah direncanakan perusahaan dapat tercapai dengan baik.

Dengan disiplin kerja secara tidak langsung juga akan mempengaruhi kinerja suatu karyawan dan perusahaan. Karena kinerja merupakan salah satu indikator kemajuan suatu perusahaan dalam tingkatpenyelesaian suatu pekerjaan baik secara kualitas ataupun kuantitas agar selalu terjaga dari waktu kewaktu. Dapat dikatakan kinerja 
merupakan standar hasil kerja yang dapat dicapai oleh seseorang atau kelompok orang dalam rangka mencapai tujuan suatu organisasi bersangkutan secara legal, tidak melanggar hukum, dan sesuai dengan moral maupun etika.

Faktor sumberdaya manusia (human resource) dalam masalahiniyaitu karyawan, dimanakaryawan merupakan peran yang sangat penting dalam perusahaan dan departemen personalia (human resourcedepartement) perlu mencermati kebutuhan para karyawan dengan baik dan bijak. Salah satunya adalah dengan menempatkan pegawai pada posisi yang sesuai kualifikasi dan kemampuan yang dimiliki. Seperti karyawan dengan kemampuan akuntansi, dia akan cocok dengan posisi keuangan, dan apabila karyawan tersebut diposisikan pada marketing maka karyawan tersebut akan sulit berkembang yang akhirnya mempengaruhi kinerja perusahaan.

Berdasarkan fenomena-fenomena diatas penulis ingin melakukan penelitian yang berkaitan dengan fenomena tersebut dengan judul "Pengaruh Disiplin Kerja Terhadap Kinerja Karyawan Pada PT. Subur Makmur Sentosa, Cabang Cikupa Tangerang”.

\section{B. Pembatasan Masalah}

Agar masalah yang menjadi objek penelitian ini tidak menyimpang dari judul diatas, maka diperlukan pembatasan masalah. Sebab, masalahmasalah yang di hadapi pada hakikatnya banyak dan bersifat kompleks, sehingga pembatasan masalah yang penulis inginkan pada lingkup: Disiplin Kerja dan Kinerja Karyawan pada PT. Subur Makmur Sentosa, Tangerang.

\section{Perumusan Masalah}

Atas dasar permasalahan yang sudah dipaparkan diatas, peneliti ingin melakukan penelitian dengan rumusan penelitian yang dirumuskan dalam pertanyaan sebagai berikut:

1. Bagaimana Disiplin Kerja berpengaruh pada PT. Subur Makmur Sentosa, Cabang Cikupa Tangerang?

2. Bagaimana Kinerja Karyawan berpengaruh pada PT. Subur Makmur Sentosa, Tangerang?

3. Bagaimana Disiplin Kerja dan kinerja berpengaruh pada PT. Subur Makmur Sentosa, Tangerang?

\section{Tujuan Penelitian}

Dari uraian perumusan masalah diatas, makatujuan dari penelitian ini yang akan dicapai oleh penulis dalam penelitian ini adalah:

1. Untuk mengetahui bagaimana disiplin kerja pada PT. Subur Makmur Sentosa, Cabang Cikupa Tangerang.

2. Mengetahui bagaimana kinerja karyawan pada PT. Subur Makmur Sentosa, Cabang Cikupa Tangerang.

3. Untuk mengetahui bagaimana pengaruh antara Disiplin kerja dan Kinerja Karyawan di PT. Subur Makmur Sentosa, Tangerang Cabang Cikupa.

\section{E. Manfaat Penelitian}

Penelitian ini dapat dijadikan bahan pertimbangan bagi semua pihak, diantaranya dapat memberikan referensi bagi dunia akademik, perpustakaan, dan para pelaku bisnis khususnya pada PT. Subur Makmur Sentosa, cabang Cikupa Tangerang dalam memahami pentingnya suatu kedisiplinan dan kinerja karyawan.

\section{TINJAUAN PUSTAKA}

\section{A. Disiplin}

Dalam bukunya Henry Simamora (2010: hal. 610), kedisiplin merupakan proses yang mengoreksi (correct) atau menghukum (punish) bawahan karena melanggar aturan atau prosedur. Sedangkan dalam bukunya Malayu SP. Hasibuan (2013: 193), disiplin merupakan operatife function dari MSDM yang penting karena semakin baik kedisiplin karyawan, maka akan tinggi prestasi kerja yang akan dicapai. Dengan disiplin yang baik, maka organisasi perusahaan dalam mencapai hasil kerja akan maksimal.

\section{B. Kinerja}

"Kinerja diartikan sebagai hasil evaluasi terhadap pekerjaan yang dilakukan individu dibandingkan dengan kriteria yang telah ditetapkan bersama", menurut Stephen P. Robbins dalam Sinambela (2012: 5). Sedangkan menurut Rivai, Basri, Sagala, Murni dan Abdullah (2011: 14), mengemukakan bahwa kinerja adalah "hasil meningkat keberhasialan pekerja atau seluruh pekerja dalam suatu periode tertentu di dalam melaksanakan tugas dibanding dengan berbagai kemungkinan seperti penilaian standar hasil kerja, target yang dicanangkan organisasi atau sasaran 
atau kriteria yang telah ditentukan terlebih dahulu oleh organisasi”.

\section{Kerangka Pemikiran}

Sugiono dalam bukunya (2014: hal. 93), "menyatakan bahwa kerangka berfikir merupakan model konseptual tentang bagaimana teori berhubungan dengan berbagai faktor yang telah diidentifikasi sebagai masalah yang penting ". Model yang dibuat oleh penulis dalam kerangka pemikiran adalah sebagai berikut:

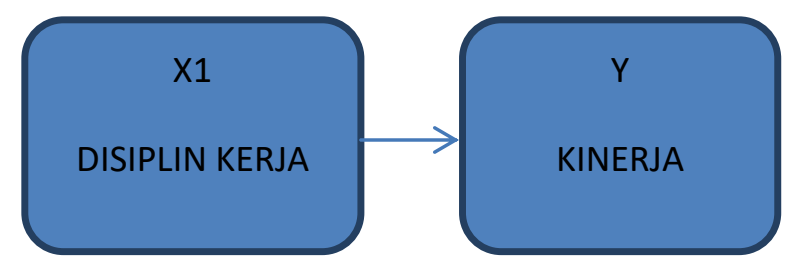

D.

\section{Hipotesis}

Dalam bukunya Kerlinger (2006: 30), hipotesis atau hipotesa adalah "peryataan dugaan (conjectural) mengenai hubungan atau relasi antara 2 (dua) variabel atau lebih". Hipotesis akan mengambil bentuk kalimat pernyataan (declarative) dan menghubungkan secara umum maupun khusus variabel yang satu dengan variable yang lain. Hipotesis dalam penelitian ini dirumuskan sebagai berikut:

$\mathrm{H}_{1} \mathrm{Y}$ : Apakahada pengaruh yang positif dansignifikanantara disiplin kerja dan kinerja karyawan pada PT. Subur Makmur Sentosa.

\section{METODE PENELITIAN}

\section{A. Tempat dan Waktu Penelitian}

Penelitian yang dilakukan olehpeneliti berlokasi di PT. Sumber Makmur Sentosa, Cabang Cikupa Tangerang, yang beralamat di Jalan. Raya Serang Km.15 Cikupa, Kabupaten Tangerang-Banten. Alokasi waktu dalam penelitian ini selama 3 (tiga) bulan dari bulan OktobersampaidenganbulanDesember 2017 yang digunakan untuk mencari dan menggali informasi pada semua karyawan yang bekerja pada PT. Subur Makmur Sentosa cabang Cikupa.

\section{B. Metode Penelitian}

Dalam melakukan pendekatan penelitian ini, penulis melakukan pendekatan diantaranya diawali dengan mengumpulkan data-data melalui penyebaran kuesioner kepada seluruh karyawan yang sudah dijadikan responden, menentukan instrumen penelitian, menentukan metode yang yang akan dipergunakan, serta menganalisis data yang sudah dikumpul (college).

\section{Populasi dan Sampel}

Datayangdiperolehuntukmementukanjumla hresponden, makapenelitimencari populasi dan sampel yang digunakan dalam penelitian ini denganmenggunakan sampel jenuh, dimana jumlah populasi yang ada semuanya dijadikan sampel. Jadi sampel yang digunakan adalah sebanyak 85 karyawan PT. Subur Makmur Sentosa cabang Cikupa. Dari sampel yang digunakan sebanyak 85 orang ini kesemuanya adalah karyawan tidak termasuk posisi jabatan Manajer dan Top Manajer, Direktur, serta Pemilik (Owner) perusahaan.

\section{Teknik Penentuan Data}

Teknik yang digunakan dalam penentuan data penelitian ini, terdiri dari:

1. Data Primer, yaitu dengan menyebar seluruh angket kuesioner yang dibagikan kepada seluruh karyawan.

2. Data Sekunder, data yang diperoleh dari literatur-literatur dari berbagai sumber diantarannya melalui buku, jurnal, internet dan perpustakaan.

\section{E. Metode Analisis Data}

Metode yang digunakan dalam penelitian ini adalah:

\section{Analisis data}

Pelaksanaan pengujian data ini dikarenakan pada sumber data yang sudah ditentukan dalam organisasi perusahaan pada PT. Subur Makmur Sentosa cabang Cikupa yaitu sebanyak 85 orang responden.

hasil uji validitas dengan menggunkan rumus product moment terhadap masing-masing variabel penelitian disajikan secara lengkap dan akurat dimana $r_{\text {hitung }}>r_{\text {table. }}$. Sedangkan dalam uji reliabilitas dengan menggunakan rumus cronbach alpha, dimana menurut Soegiono (2013: 184) data dikatakan realibel apabila hasil perhitungan Cronbach-Alpha $\geq 0.6$. 


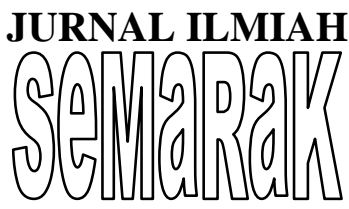

2. Analisis Regresi-Linier Sederhana

Analisis regresi linier sederhana adalah pengaruh secara linier antara variabel $X$ dan variabel $\mathrm{Y}$. Data yang digunakan biasanya berskala interval atau ratio dengan mengunakan rumus:

$\mathrm{Y}=\mathrm{a}+\mathrm{bX}$

Keterangan:

$\mathrm{Y}=$ Variabel dependent (terikat)

$\mathrm{X}=$ Variabel independent (bebas)

$\mathrm{a}=$ Konstanta (nilai $\mathrm{Y}$ apabila $\mathrm{X}=0$ )

$\mathrm{b}=$ Koefisien regresi

\section{Koefisien Korelasi}

Dalam bukunya, Soegiono (2015: hal. 183) "korelasi sendiri merupakan angka yang menunjukan arah dan kuatnya hubungan antara dua variabel atau lebih". Dalam penelitian ini untuk mengetahui seberapa besar pengaruh disiplin kerja terhadap kinerja karyawan dapat menggunakan analisis koefisien korelasi.

4. Koefisien Determinasi $\left(r^{2}\right)$

Yang dimaksud dengan koefisien korelasi adalah "kemampuan-kemampuan variabel tidak bebas yang diukur dengan besarnya koefisien determinasi",caraini dapat dilakukandenganmenggunakan rumus:

$\mathrm{DD}=\mathrm{r}^{2} \times 100 \%$

Keterangan:

$\mathrm{KD}=$ Koefisien determinasi

$r^{2}=$ Koefisien korelasi $X$ dan $Y$

\section{HASIL PENELITIAN}

\section{Uji Validitas}

Berdasarkan perhitungan dengan menggunakan SPSS versi 21.0 didapat nilai ratarata $r_{\text {hitung }}$ sebesar 0,562. Berdasarkan $r_{\text {tabel }}$ dengan responden 85 orang dan 20 pertanyaa, maka nilai $\mathrm{r}_{\text {tabel }}$ adalah 0,213. Sehingga perhitungan tersebut dinyatakan valid karena nilai $r_{\text {hitung }}>r_{\text {tabel }}(0,562>$ 0,213 ) pada variabel $X$ (Disiplin kerja).

Sedangkan hasil rata-rata perhitungan validitas pada variabel kinerja karyawan adalah sebesar $r_{\text {hitung }} 0,635$ sehingga semua pertanyaan pada variabel $\mathrm{Y}$ dinyatakan valid, dimana $\mathrm{r}_{\text {hitung }}>$ $\mathrm{r}_{\text {tabel }}(0,635>0,213)$.

\section{Uji Regresi Linier Sederhana}

Berdasarkanhasilpengolahan

denganmenggunakan

data

didapatnilaiconstantpadaDisiplinkerja (X) sebesar $\mathrm{B}=50,866$ dannilai DenganbentukRegersi linier sederhana $\mathrm{Y}=\mathrm{a}+\mathrm{bX}$, makasetelahdimasukanhasildaripengolahan data menjadi $\mathrm{Y}=50,866+0,305 \mathrm{X}$ yang berarti bahwa perubahan $\mathrm{Y}$ berjalan ke arah perubahan X. Jadi setiap kenaikan nilai $X$ diikuti oleh peningkatan nilai $\mathrm{Y}$, begitu pula sebaliknyaapabilanilai $\mathrm{X}$ menurun, makanilai $\mathrm{Y}$ jugaakanikutmenurun. Kesimpulannyaadalah, apabilanilai Y adapeningkatansebesar 1 (satu), makanilai $\mathrm{Y}$ akannaiksebesar 0,305.

\section{Uji Koefisien Korelasi}

Berdasarkan perhitungan dengan menggunakan product moment pearson, maka didapat hasil dari pengaruh variable $X$ terhadap variable $\mathrm{Y}$ sebesar $\mathrm{r}=0,698$. Yang artinya terjadi pengaruh disiplin kerja (X) terhadap kinerja (Y)padakaryawan dengan besarnya pengaruh sebesar 0,698. Didalam interprestasi koefisien korelasi apabila hasil Interval koefisien dalam interval 0,60-0,799 maka tingkat hubungannya adalah kuat, (Sugiyono, 2011: 184).

\section{Uji Koefisien Determinasi $\left(r^{2}\right)$}

Dalam perhitungan dengan menggunakan SPSS, menunjukan pada tabel summary untuk mengetahui $\mathrm{r}^{2}$ atau R-squeremaka didapat hasil $\mathrm{r}^{2}$ sebesar 48 yang artinya 48\%. Sehingga koefisien determinasi yang terbentuk dari pengaruh disiplin kerja terhadap kinerja karyawan sebesar $48 \%$ dan sisanya sebesar $52 \%$ dipengaruhi oleh faktorfaktor lain diluar dari penelitian ini.

\section{Hipotesis}

Dari perhitungan menggunakan SPPS, dimana thitung sebesar 8,879 lebih besar dari pada $\mathrm{t}_{\text {tabel }}$ sebesar1,989, maka hasil tersebut menunjukan hasil yang signifikan dengan kata lain thitung $>\mathrm{t}_{\text {tabel }}$. Sehingga hipotesis diterima $\left(\mathrm{H}_{0}\right.$ ditolak dan $\mathrm{H}_{\mathrm{a}}$ diterima).

\section{KESIMPULAN}

Jadi dapat disimpulan dari hasil dan pembahasan dalam tulisan di atas tentang pengaruh Kedisiplinan terhadap Kinerja Karyawan di PT. Subur 


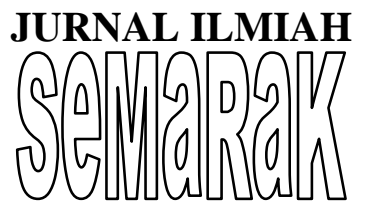

Makmur Sentosa, Tangerang, maka dapat ditarik kesimpulan sebagai berikut :

1. Hasil perhitungan dengan olah data SPSS, terdapat pengaruh yang positif dan signifikan diantara Disiplin Kerja (X) sebagai variabel bebas dengan Kinerja Karyawan (Y) sebagai variabel terikat pada PT. Subur Makmur Sentosa cabang Cikupa Tangerang secara parsial, sehingga hipotesis diterima. Dimana thitung 8,879> t tabel 1,989 dengan persentase tingkat pengaruhsebesar 48\%, maka dapat disimpulkan hipotesis dalam penelitian ini diterima (Ha=Diterima).

2. Hasil persentasi penagaruh disiplin kerja terhadap kinerja karyawan dari 85 responden yang dijadikan sampel dengan membuat 20 butir pertanyaan dari masing-masing variabel pengaruh yang terjadi sebanyak $48 \%$, dan sisanya sebanyak $52 \%$ dipengaruhi variabel lain diluar penelitian.

3. Hipotesis yang terbentuk dalam penelitian ini dimana $t_{\text {hitung }}$ sebesar $8,879>t_{\text {table }} 1,979$, sehingga hipotesis dalam penelitian ini diterima.

\section{DAFTAR PUSTAKA}

Algifari. 2010. Analisis Regresi, Teori, Kasus dan Solusi, Edisi Kedua. Yogyakarta: BPFE UGM.

Ghozali, Imam. 2011. Aplikasi Analisis Mulitivarate Dengan Program IBM SPSS, Edisi Kelima. Semarang: Univ. Diponegoro.

Goal, Chr. Jimmy. 2014. A to Z Human Capital, Manajemen Sumber Daya Manusia. Jakarta: Penerbit Gramedia.

Hasibuan, Melayu. S.P. 2009, Manajemen Sumber Daya Manusia, Jakarta: Penerbit Bumi Aksara.

Pramono. Agus, 2012, Pengaruh Kompensasi, Motivasi, Lingkungan Kerja dan Kepemimpinan Terhadap Kinerja Karyawan, Semarang: PT. Adi Mitra Pratama.

Robbin, Stephen. dan Sinambela. 2012, Perilaku Organisasi, Edisi Duabelas, Jakarta: Ahli Bahasa, Diana Angelica, Salemba Empat.

Siagian. P. Sondak. 2003, Manajemen Sumber Daya Manusia. Jakarta: Bumi Aksara.
Sugiyono. 2012. Metode Penelitian Bisnis: Pendekatan Kuantitatif, Kualitatif, dan $R$ dan D. Bandung: Alfabeta.

Sugiono dan Wibowo. 2002. Statistik Penelitian, Edisi Pertama. Bandung: Alfabeta.

Simamora, Henry. 2012, Manajemen Sumber Daya Manusia, Edisi Pertma, Yogyakarta: STIE YKPN Yogyakarta. 